\title{
A high efficient integrated planar transformer for primary-parallel isolated boost converters
}

Sen, Gökhan; Ouyang, Ziwei; Thomsen, Ole Cornelius; Andersen, Michael A. E.; Møller, Lars

Published in:

Energy Conversion Congress and Exposition

Link to article, DOI:

10.1109/ECCE.2010.5618405

Publication date:

2010

Document Version

Publisher's PDF, also known as Version of record

Link back to DTU Orbit

Citation (APA):

Sen, G., Ouyang, Z., Thomsen, O. C., Andersen, M. A. E., \& Møller, L. (2010). A high efficient integrated planar transformer for primary-parallel isolated boost converters. In Energy Conversion Congress and Exposition (pp. 4605-4610). IEEE. https://doi.org/10.1109/ECCE.2010.5618405

\section{General rights}

Copyright and moral rights for the publications made accessible in the public portal are retained by the authors and/or other copyright owners and it is a condition of accessing publications that users recognise and abide by the legal requirements associated with these rights.

- Users may download and print one copy of any publication from the public portal for the purpose of private study or research.

- You may not further distribute the material or use it for any profit-making activity or commercial gain

- You may freely distribute the URL identifying the publication in the public portal 


\title{
A High Efficient Integrated Planar Transformer for Primary-Parallel Isolated Boost Converters
}

\author{
Gokhan Sen ${ }^{1}$, Ziwei Ouyang ${ }^{1}$, Ole C. Thomsen ${ }^{1}$, Michael A. E. Andersen ${ }^{1}$, and Lars Møller ${ }^{2}$ \\ 1. Department of Electrical Engineering, \\ Technical University of Denmark, \\ Kgs. Lyngby, DK-2800, Denmark, zo@elektro.dtu.dk \\ 2. H2 Logic A/S \\ Herning, DK-7400, Denmark
}

\begin{abstract}
A simple, easy to manufacture and high efficient integrated planar transformer design approach for primary parallel isolated boost converters is presented. Utilizing the same phase flux flow, transformers are integrated, reducing the total ferrite volume and core loss for the same peak flux density. Number of turns is minimized for easy manufacturing by cascade placement of planar cores increasing the effective crosssectional area. AC losses in the windings as well as the leakage inductance of the transformer are kept low by extensive interleaving of the primary and secondary turns. The idea of transformer integration is further extended to multiple primary power stages using modular geometry of the planar core, further reducing the core loss and allowing a higher power density. To verify the validity of the design approach, a 4-kW prototype converter with two primary power stages is implemented for a fuel cell fed battery charger application with 50-110 $\mathrm{V}$ input and 65-105 V output. Input inductors are coupled for current sharing, eliminating the use of current sharing transformers. An efficiency of $94 \%$ is achieved during nominal operating condition where the input is $70-\mathrm{V}$ and the output is $84-\mathrm{V}$.
\end{abstract}

Index Terms-planar integrated magnetics, coupled inductor, isolated boost converter, fuel cell.

\section{INTRODUCTION}

Traction drive systems based on fuel cells and batteries require the dc-dc converter components to be selected for a wide range of input and output voltages depending on the fuel cell current and battery state-of-charge. This requirement limits the efficiency compared to a converter optimized around an operating point since the components have to be selected to cover the limits. So the dc-dc converter should be designed carefully to compensate for this situation [1].

Transformer design is a critical stage in high performance dc-dc converter design. In isolated boost converter applications, leakage inductance of the transformer should be minimized as well as the ac resistance since it causes spikes on the primary switch voltages increasing the inductive clamp losses [2]. Planar transformers have unique advantages in terms of increased power density, better cooling capability, modularity and manufacturing simplicity which make them attractive for high current dc-dc converter applications [3], [10]. In [4] and [5] integrated planar transformers for dc-dc converters have been studied. Improvements of AC resistance in transformer design are presented in [7], [8] and [9]. Also optimal design of transformers in high power, high frequency applications is mentioned in [11], [12] and [15].

Recently, significant achievements have been obtained in simple, low cost and high performance paralleling of converters for handling high currents in fuel cell applications which are presented in [13] and [14].

In this paper a new approach in transformer design for primary-parallel secondary-series isolated boost converters is presented. The idea is verified by simulation and experimental results.

\section{Primary Parallel Isolated Boost CONVERTER}

Boost derived topologies are preferred in fuel cell applications due to their low input current ripple. Fig. 1 shows a primary parallel isolated boost derived topology suitable for handling high input currents for fuel cell applications. The dc current is forced to be equal in both primary stages by the series secondary connection of the two transformers. In order to compensate for the non-zero differential voltages in the two power stages that may occur due to gate signaling delays or parameter mismatches, a direct coupled input inductor is used, instead of a current sharing transformer. This coupled inductor divides the input current into two parts reducing the conduction losses and integrating two windings into a single core with a greater equivalent inductance.

In this topology, primary power stages share the same control signals with same phase switching sequence for the corresponding switches which allows a simpler control. Output rectification unit as well as input and output filters are common to both of the primary stages. Details of this topology and basic waveforms are presented in [2] and [13].

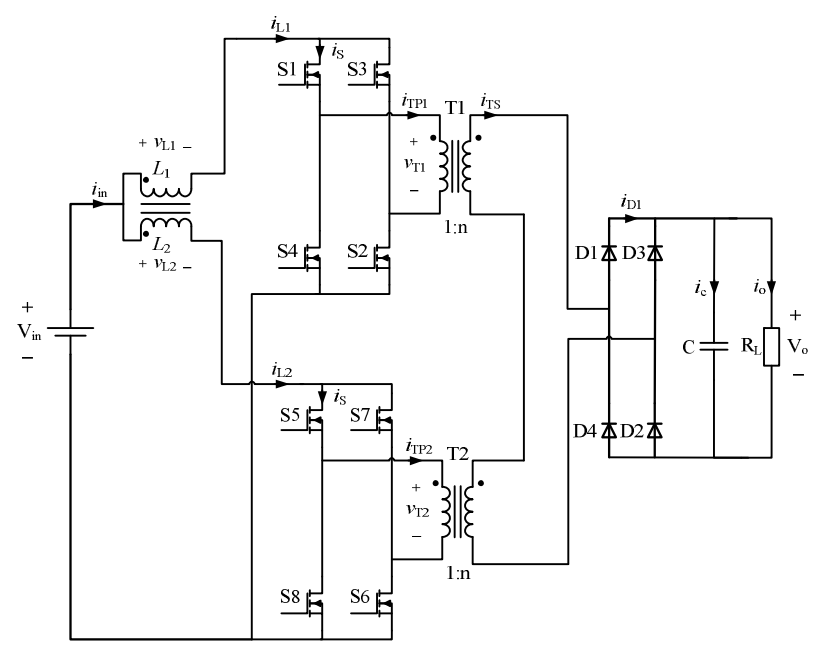

Fig. 1. Primary parallel isolated boost converter with coupled inductors for current sharing 
Transformers $T_{1}$ and $T_{2}$ have the same number of turns with the same core size and material. Since the ac current sharing is ensured by the input coupled inductor, the same flux flows in both transformer cores. If it would be possible to wind both of the windings into the same core, they would produce the same peak flux density which would correspond to half the core loss since the total volume of ferrite is halved. But this method is not practical for standard E-cores due to the limited winding space; however it is possible to be achieved using planar E- cores by utilizing their modularity.

\section{TRANSFORMER DESIGN}

This section presents the new integrated planar transformer designed for the primary parallel isolated boost converter in Fig. 1, based on the arguments in the previous section. The new design provides higher power density, lower cost and higher efficiency compared to two separate transformers with the same core type. Planar structure also allows PCB windings to be used which make the manufacturing simpler and cheaper considering volume production. Also it allows easier realization for the interleaved winding arrangement.

\section{A. Winding arrangement}

Winding losses in transformers increase dramatically with increasing frequency due to skin and proximity effects. Based on Dowell's assumptions and the general field solutions for the distribution of current density in a single layer of an infinitely long foil conductor, the expression for $\mathrm{AC}$ resistance of a certain layer can be derived as in [6] and [9],

$$
R_{a c, m}=R_{d c, m} \cdot \frac{\xi}{2}\left[\frac{\sinh \xi+\sin \xi}{\cosh \xi-\cos \xi}+(2 m-1)^{2} \cdot \frac{\sinh \xi-\sin \xi}{\cosh \xi+\cos \xi}\right]
$$

where $\xi$ is defined as

$$
\xi=\frac{h}{\delta}
$$

and $\delta$ is the skin depth for a specific frequency, which is given by

$$
\delta=\frac{1}{\sqrt{\pi \cdot f \cdot \mu \cdot \sigma}}
$$

$m$ is defined as

$$
m=\frac{F(h)}{F(h)-F(0)}
$$

where $F(0)$ and $F(h)$ are Magneto Motive Forces (MMF) at the limits of a layer as shown in Fig. 2. The first term in equation (1) describes the skin effect and the second term represents the proximity effect. The proximity effect loss in a multilayer winding, may strongly dominate the skin effect loss if the value of $\mathrm{m}$ increases which is related to the winding arrangement. Interleaving transformer windings can reduce the proximity loss significantly (decrease $m$ ) when the primary and secondary currents are in phase. In this research
3:1 turns ratio is used for each transformer. There are 3 turns in series on the primary side; and a single turn with four layers in parallel on the secondary side to sustain high current. Fig. 2 shows the MMF distributions along the vertical direction for the interleaved arrangement of the designed transformer. Fig. 3 shows the AC resistance relative to the DC resistance in a layer having a thickness equal to the skin depth. The layer thickness can be selected for minimizing the AC losses according to the value of $\mathrm{m}$. In this case switching frequency is $50-\mathrm{kHz}$ and $0.14-\mathrm{mm}$ PCB layer thickness has been chosen for each layer.

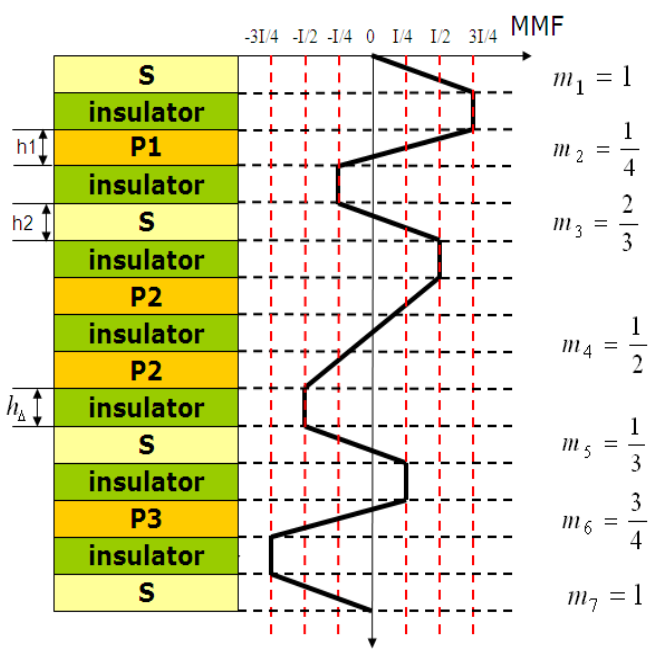

Fig.2. MMF distributions for interleaved arrangement for the proposed transformer.

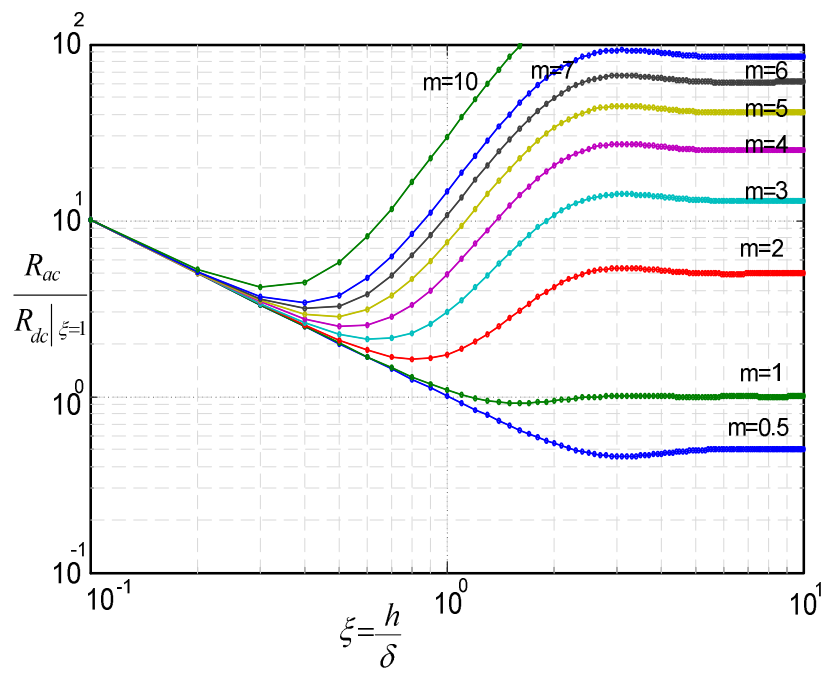

Fig. 3. AC resistance relative to dc resistance in a layer with different values of thickness over skin depth.

\section{B. Cascaded structure}

Proposed integrated planar transformer has been built using a cascaded core structure to minimize the number of turns. Fig. 4 shows the construction of each transformer with two planar E-cores placed side-by-side which adds up to four 
E-cores and two I-cores for the whole integrated structure. Increased cross-section by cascading avoids saturation and reduces core loss when the same number of turns is used in a non-cascaded (single) core construction. According to Faraday's law peak-to-peak flux density is,

$$
\Delta B=\frac{V \cdot \Delta t}{N \cdot A_{e}}
$$

where $N, A_{e}$ are the number of turns and the cross-section of centre leg of the core respectively. $V \cdot \Delta t$ is volt-seconds applied to the transformers. Core loss of a transformer depends on the material that the core is made from, the switching frequency, the flux density, and the volume of the core. The Steinmetz Equation can be used to compute the core loss given in equation (6),

$$
P=K \cdot f^{\alpha} \cdot(\Delta B / 2)^{\beta} \cdot V_{e}
$$

$K, \alpha$ and $\beta$ are constants that are provided by the manufacturer or can be calculated from the curves of a specific core loss data. Combining equation (5) with equation (6) and having the ratio of the two different cases,

$$
P_{c c}=2^{1-\beta} \cdot P_{c o}
$$

where $P_{c c}$ and $P_{c o}$ represent the core losses of 2 cores cascaded transformer and a single core transformer with the same number of turns, respectively. Generally $\beta$ is more than 1 , therefore the cascaded transformer has lower core loss according to eqn. (7). It has to be noted that winding loss will be sacrificed due to longer turn lengths. In this work $3 \mathrm{~F} 3$ core material is used which has $\beta$ approximately equal to 2.6.

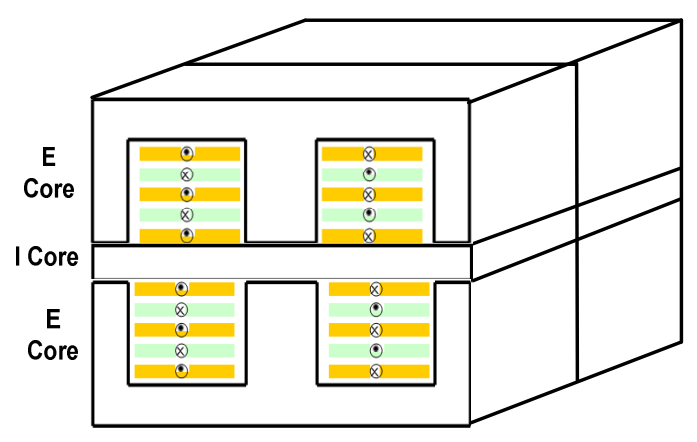

Fig.4. Two transformers in E-I-E integration.

\section{Magnetics Integration}

In order to reduce the transformer footprint area and increase the converter power density, transformers $T_{1}$ and $T_{2}$ in Fig. 1 are integrated utilizing the modular flexibility of the planar cores. The new structure is shown in Fig. 4. Two integrated transformers are located on top of each other. Two cascaded I-cores are shared in the centre part. The symmetrical windings of the two transformers will allow the flux in the I-cores to be cancelled which reduce the core loss. 3D FEA simulation result in Fig.7 shows the flux in I-core (centre part) to be almost zero. More transformers can be integrated based on this principle which will further reduce the overall core loss since the flux will only flow in the outer core sections (Fig. 5).

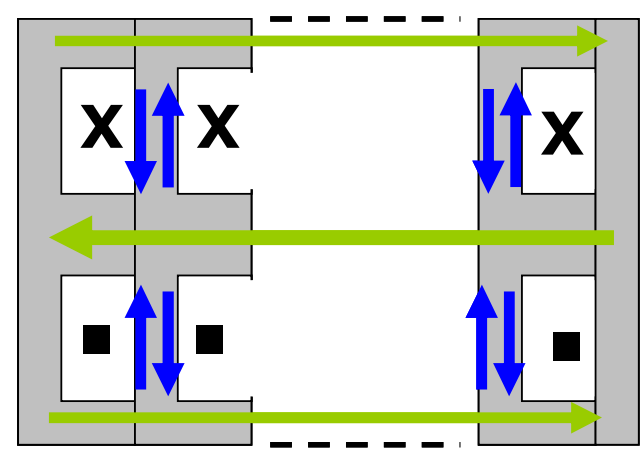

Fig.5. Integration of $n$ number of transformers with main flux lines (green) and cancelled flux lines (blue).

\section{Magnetic reluctance model}

Fig. 6 shows the magnetic reluctance model of the integrated structure where $R_{1}$ and $R_{2}$ are the reluctances of outer legs of E-core and half I-core respectively. Similarly $R_{c}$ represents the reluctance of the center leg of E-core.

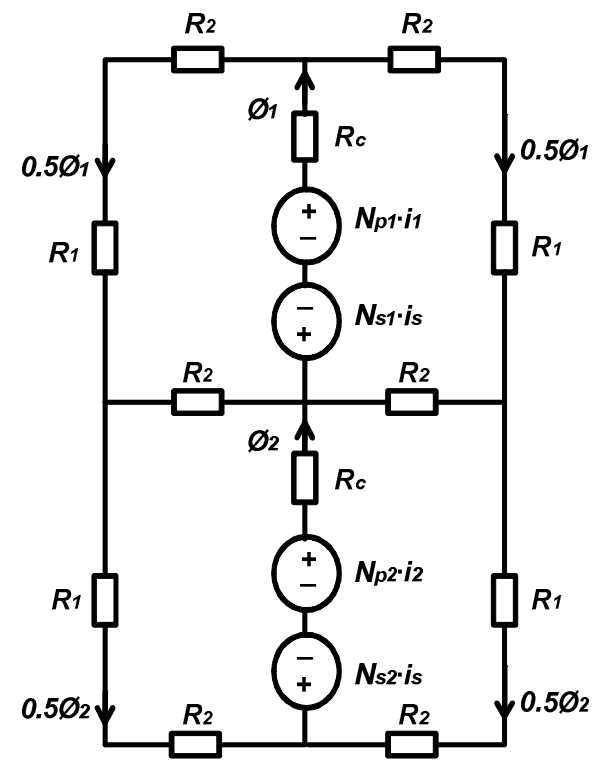

Fig.6. Reluctance model of the integrated transformer.

Based on the equivalent magnetic model in Fig.6, major flux directions can be determined. In order to calculate the magnetizing inductance of the integrated module referred to the secondary side, the equations (8) and (9) can be obtained assuming the primary windings to be shorted,

$$
\begin{aligned}
& N_{s 1} \cdot i_{m s}=\phi_{1} \cdot R_{c}+0.5 \cdot \phi_{1} \cdot\left(R_{1}+R_{2}\right)+0.5 \cdot\left(\phi_{1}-\phi_{2}\right) \cdot R_{2} \\
& N_{s 2} \cdot i_{m s}=\phi_{2} \cdot R_{c}+0.5 \cdot \phi_{2} \cdot\left(R_{1}+R_{2}\right)+0.5 \cdot\left(\phi_{2}-\phi_{1}\right) \cdot R_{2}
\end{aligned}
$$

where $i_{m s}$ is the magnetizing current referred to the secondary side. Since the two transformers, $T_{1}$ and $T_{2}$ are identical, 
$\varnothing_{1}=\varnothing_{2}$ and $N_{s 1}=N_{s 2}$ can be used. Therefore, the magnetizing inductance of each transformer in the integrated module referred to the secondary side can be derived as,

$$
L_{m}^{\prime}=\frac{2 N_{s}^{2}}{2 R_{c}+R_{1}+R_{2}}
$$

The magnetizing inductance of a single separated transformer would have the following expression,

$$
L_{m}=\frac{2 N_{s}^{2}}{2 R_{c}+R_{1}+2 R_{2}}
$$

Comparing magnetizing inductances of the integrated and separated transformers using (10) and (11), $L_{m}^{\prime}>L_{m}$ can be observed which means the integrated transformers have higher magnetizing inductance compared to the separated case. This is because of the fact that the flux cancellation occurs in the shared I-core effectively reducing the length of flux path. Higher magnetizing inductance reduces the magnetizing current which helps in the current stress over the components.

\section{E. Measurement results}

Fig. 8 and Fig.9 show the leakage inductance and AC resistance measurement results of the designed single transformer and the integrated transformers respectively using PSM1735 impedance analyzer. For the single transformer, the leakage inductance is $25.76-\mathrm{nH}$ and the AC resistance is $2.50-\mathrm{m} \Omega$ referred to secondary side when the frequency is $50-\mathrm{kHz}$. This measurement has been taken by shorting the primary side and connecting the secondary terminals to the impedance analyzer. For the integrated transformers, the total leakage inductance referred to the secondary side is $40.25-\mathrm{nH}$ and the total AC resistance is $5.53-\mathrm{m} \Omega$. Fig. 10 shows the measurement results of magnetizing inductances. Results confirm the previous analysis that the total magnetizing inductance of the two integrated transformers is greater than that of the two series connected separated transformers.

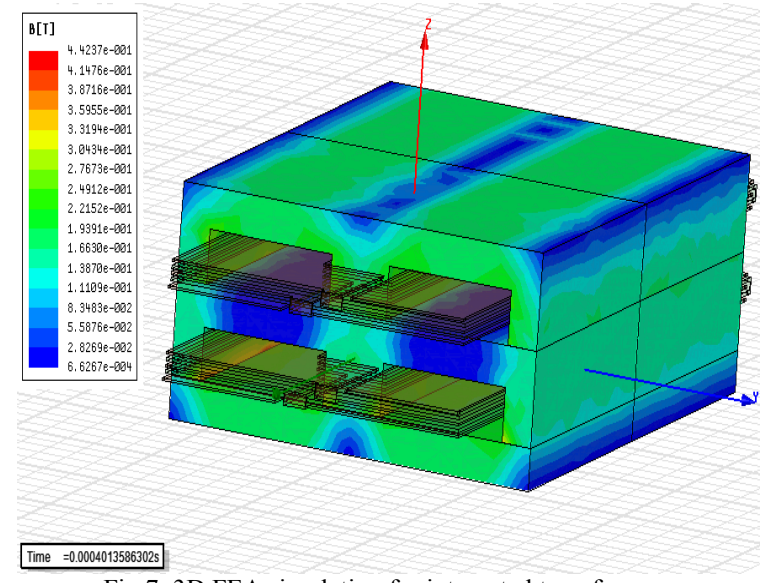

Fig.7. 3D FEA simulation for integrated transformers

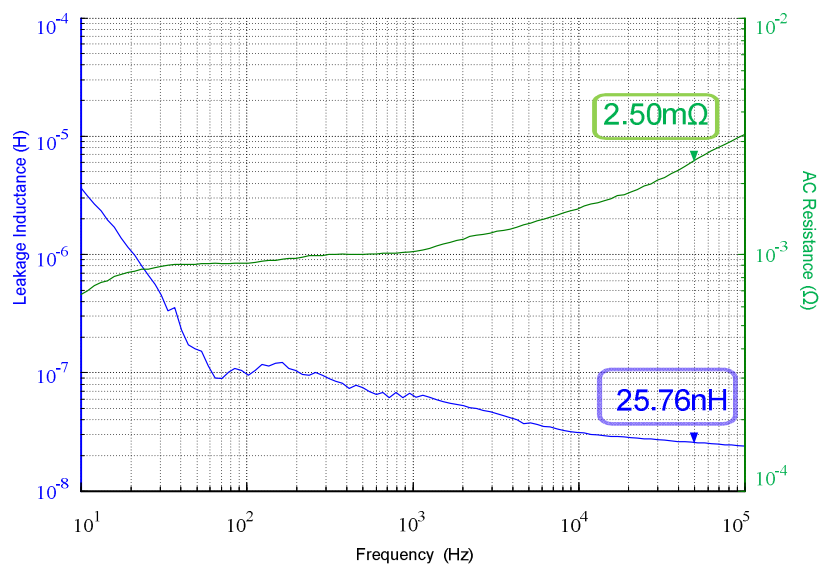

Fig.8. Measurement results of ac resistance and leakage inductance of a single transformer referred to the secondary side

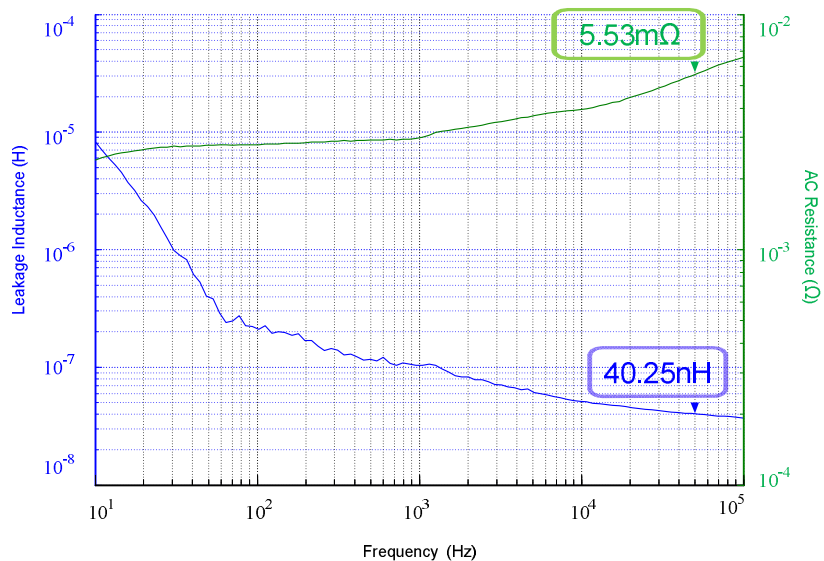

Fig.9. Measurement results of ac resistance and leakage inductance referred to the secondary side for the deigned integrated transformer

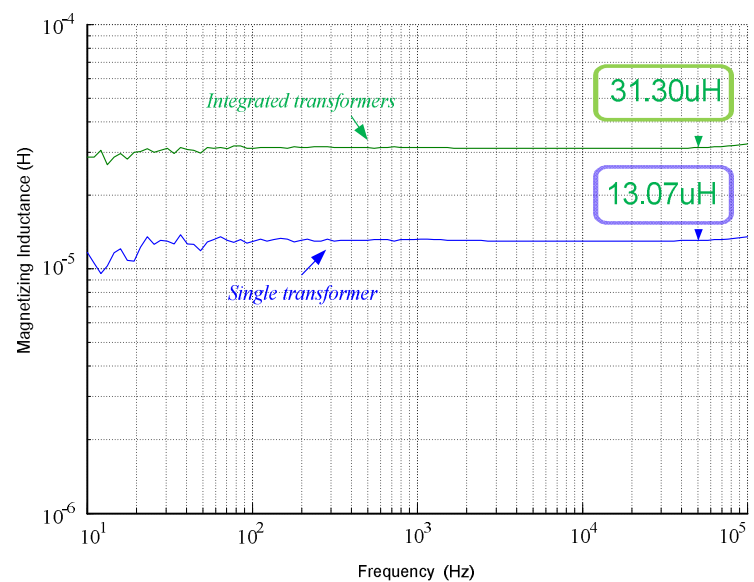

Fig.10. Measurement results of magnetizing inductances of both single and integrated transformers referred to secondary side

Table I summarizes the design parameters for the integrated transformer. Each PCB winding has 8 layers where 4 layers used in parallel for the single secondary turn and the remaining 4 layers are used for three primary turns with one of the turns used two layers in parallel. 
Table I

Design parameters for the integrated transformers

\begin{tabular}{|c|c|}
\hline Parameters & Values \\
\hline Number of turns in primary of $\mathrm{T}_{1}\left(N_{p_{l}}\right)$ & 3 \\
\hline Number of turns in primary of $\mathrm{T}_{2}\left(N_{p_{2}}\right)$ & 3 \\
\hline Turns ratio of each transformer & $3: 1$ \\
\hline Planar Core type & EILP 64 \\
\hline Core material & $3 \mathrm{~F} 3$ \\
\hline $\begin{array}{c}\text { Number of layers of PCB winding } \\
\text { winding }\end{array}$ & 8 \\
\hline $\begin{array}{c}\text { AC resistance referring to the secondary side } \\
\text { Leakage inductance referring to the } \\
\text { secondary side }\end{array}$ & $5.53 \mathrm{OZ} \Omega$ \\
\hline $\begin{array}{c}\text { Magnetizing inductance referring to the } \\
\text { secondary side }\end{array}$ & $40.25 \mathrm{nH}$ \\
\hline
\end{tabular}

\section{EXPERIMENTAL RESULTS}

A 4-kW prototype converter has been built to verify the new integrated transformer design approach. Input voltage is between $50-110 \mathrm{~V}$ and output voltage is $65-105 \mathrm{~V}$. Primary switches are IRF4668, 200-V, 8-m $\Omega$ power MOSFETs from International Rectifier. Output rectification is handled by 80CPQ150 schottky diodes with $0.82-\mathrm{V}$ forward voltage drop.

The two integrated transformers are implemented using four E-64 and two I-64 planar cores with 3F3 material. The primary and secondary windings are implemented using PCB windings with $0.14-\mathrm{mm}$ layer thickness.

The coupled input inductor is wound on a KoolM $\mu$ $6527 \mathrm{E} 040$ core with $0.4-\mathrm{mm}$ copper foil having 12 turns in each winding. In order to reduce the $\mathrm{AC}$ conduction losses of the inductor, $0.1 \mathrm{~mm}$ copper foil is used for a parallel inner winding with the same number of turns giving a lower AC resistance. This two parallel winding approach helps in providing a low $\mathrm{AC}$ resistance and leakage inductance path for the inductor current ripple.

IRS2110 high and low side gate drivers are used in the gate driver circuit together with ISO722C capacitive digital isolators for control signal protection. Open loop control signals are produced by TMS28027 DSP from Texas Instruments. Fig. 11 shows the implemented prototype with all the switches mounted to a heat sink beneath the converter. Output is filtered by six $20-\mathrm{uF}$ and two $820-\mathrm{nF}$ film capacitors placed very close to the rectifiers for minimizing the ac loop.

Converter waveforms are presented in Figs. 12 and 13. Coupled inductor current waveforms, $i_{L 1}$ and $i_{L 2}$, are observed to be very close in average value confirming the current sharing function of the coupled inductor. An efficiency of $94 \%$ has been observed with $70-\mathrm{V}$ input voltage, $84-\mathrm{V}$ output voltage and $3-\mathrm{kW}$ input power.

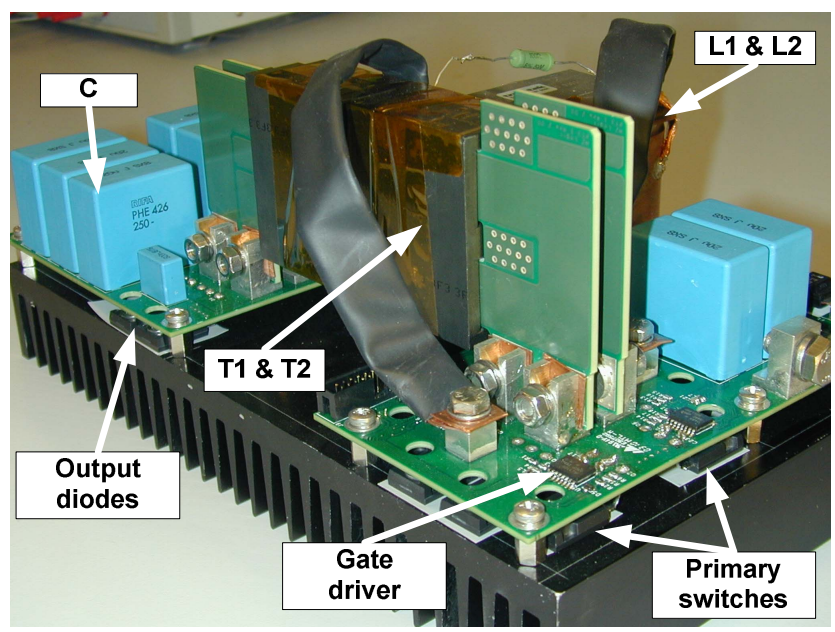

Fig. 11. Experimental prototype of integrated transformer primary parallel isolated boost converter

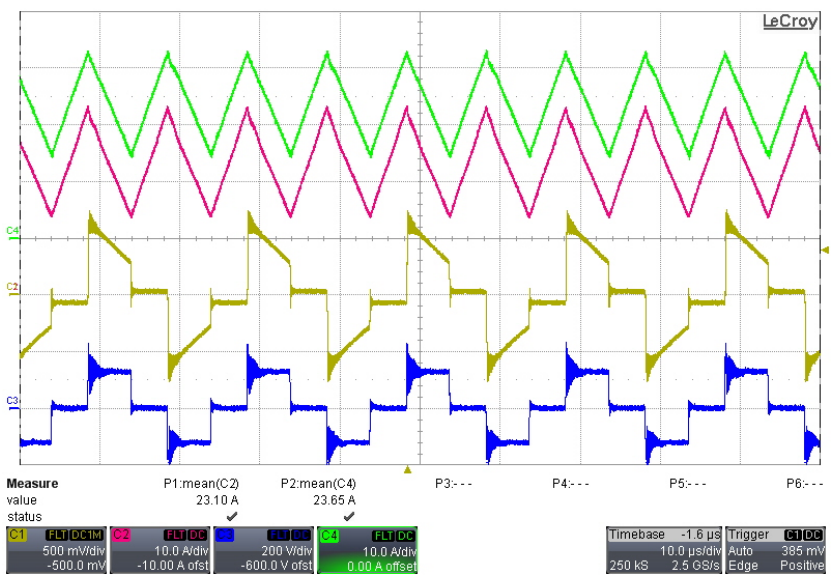

Fig. 12. Converter waveforms $\left(V_{i n}: 70 \mathrm{~V}, V_{o}: 84 \mathrm{~V}\right)$. Ch4: $i_{L 2}(10 \mathrm{~A} / \mathrm{div}), \mathrm{Ch} 2$ : $i_{L 1}(10 \mathrm{~A} / \mathrm{div}), \mathrm{Ch} 1: i_{T P 1}(25 \mathrm{~A} / \mathrm{div}), \mathrm{Ch} 3: V_{T 1}(200 \mathrm{~V} / \mathrm{div})$.

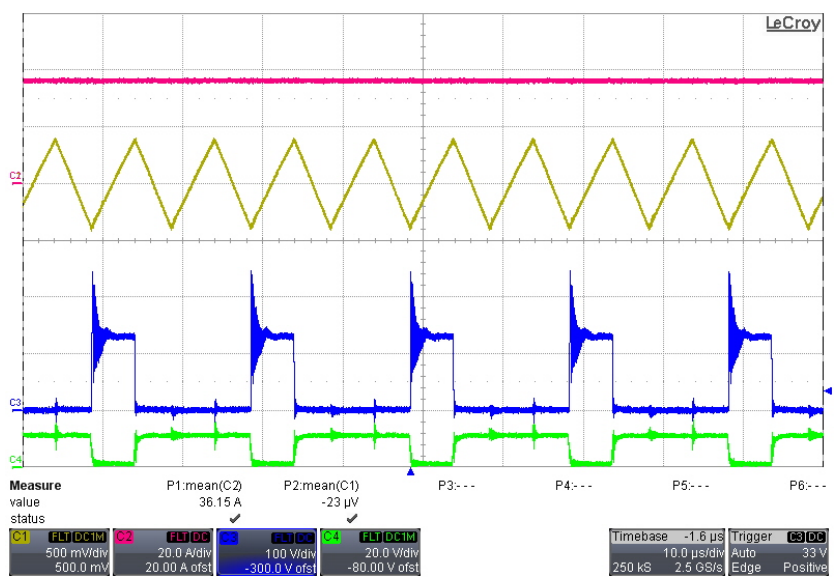

Fig. 13. Converter waveforms ( $\left.V_{i n}: 70 \mathrm{~V}, V_{o}: 84 \mathrm{~V}\right)$. Ch2: $i_{O}(20 \mathrm{~A} / \mathrm{div}), \mathrm{Ch} 1: i_{\text {in }}$ ripple (25A/div), Ch3: $V_{D S}$ of S2 (100V/div), Ch4: $V_{G S}$ of $S_{2}(20 \mathrm{~V} / \mathrm{div})$. 


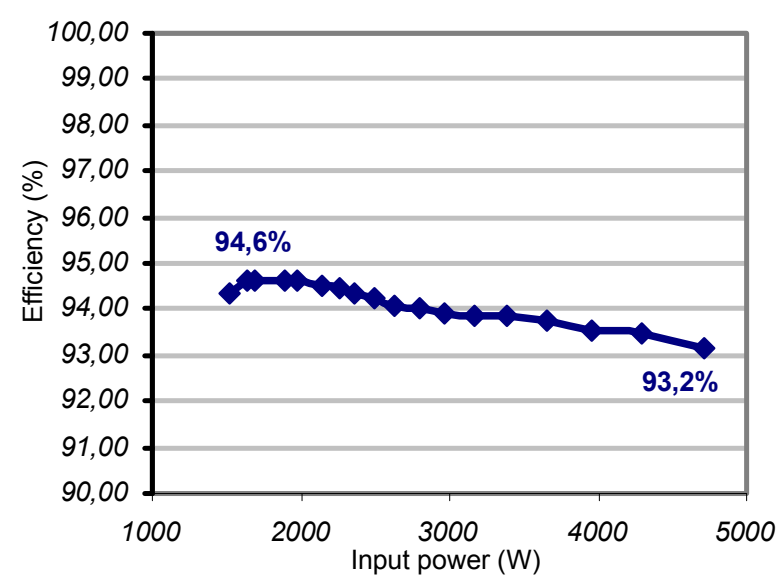

Fig. 14. Converter efficiency $\left(V_{i n}: 70 \mathrm{~V}, V_{o}: 84 \mathrm{~V}\right)$.

\section{CONCLUSION}

A new method is proposed for transformer integration in primary parallel isolated boost converters. Utilizing the symmetry and in-phase switching in each power stage, cores of the transformers have been integrated sharing the same flux. Any small difference in flux generated by each integrated transformer is compensated by the "I" cores placed in between. Number of turns is minimized by cascade placement of E cores per transformer, decreasing the effective cross sectional area. This simplifies manufacturing and decreases the winding losses. Extensive interleaving has been used for minimizing ac resistance and leakage inductance. The new integration method has been tested in a $4-\mathrm{kW}$ prototype.

\section{REFERENCES}

[1] M. Nymand and M. A. E. Andersen, "A new approach to high efficiency in isolated boost converters for high-power low-voltage fuel cell applications" in Proc. EPE-PEMC 2008, pp. 4349-4354.

[2] M. Nymand and M. A. E. Andersen, "High-efficiency isolated boost DC-DC converter for high-power low-voltage fuel-cell applications," IEEE Trans. Ind. Electron., vol. 52, no.2, pp.505-514, Feb. 2010.

[3] W. Chen, Y.-P. Yan, Y.-Q. Hu, Q. Lu, "Model and design of PCB parallel winding for planar transformer," IEEE Trans. on Magn., vol. 39, no. 5, pp.3202-3204, Sept. 2003.

[4] R.-G. Chen, J. T. Strydom, J. D. van Wyk, "Design of planar integrated passive module for zero-voltage-switched asymmetrical half-bridge PWM converter," IEEE Trans. on Ind. Appl., Vol. 39, no.36, pp.16481655, Nov.-Dec. 2003.

[5] Chen R., Canales F., Yang B., Barbosa P., van Wyk J.D., Lee F.C. "Integration of electromagnetic passive components in DPS front-end $\mathrm{dc} / \mathrm{dc}$ converter - a comparative study of different integration steps" IEEE APEC '03, vol. 2, pp. 1137-1142, Feb. 2003.

[6] P. L. Dowell, "Effects of eddy currents in transformer windings," Proc. Inst. Elect. Eng., vol. 113, no. 8, pp. 1387-1394, Aug. 1966.

[7] J. Ferreira, "Improved analytical modeling of conductive losses in magnetic components," IEEE Trans. on Power Electron., vol. 9, no. 1, pp. 127-131, Jan. 1994

[8] W. G. Hurley, E. Gath, J. G. Breslin, "Optimizing the AC resistance of multilayer transformer windings with arbitrary current waveforms," IEEE Trans. on Power Electron., vol.15, no.2, pp.369-376, Mar. 2008.

[9] X. Nan, C. R. Sullivan, "An improved calculation of proximity-effect loss in high-frequency windings of round conductors," in Proc. IEEE PESC, 2003, pp.853-860.
[10] Z.-W. Ouyang, O. C. Thomsen, M. A. E. Andersen, "The analysis and comparison of leakage inductance in different winding arrangements for planar transformer," in Proc. IEEE PEDS, 2009, pp. 1143 - 1148.

[11] R. Petkov, "Optimum design of a high-power, high-frequency transformer," IEEE Trans. on Power Electron., vol.11, no.1, pp.33-42, Jan.1996.

[12] W. G. Hurley, "Optimizing core and winding design in high frequency transformers," in Proc. IEEE CIEP, 1996, pp.2-13.

[13] M. Nymand and M. A. E. Andersen, "New primary-parallel boost converter for high-power high-gain applications" in Proc. IEEE APEC 2009, pp. 35-39.

[14] M. Nymand and M. A. E. Andersen, "A new very-high-efficiency R4 converter for high-power fuel cell applications" in Proc. IEEE PEDS, 2009, pp. $997-1001$.

[15] Z. Ouyang, O. C. Thomsen and M. A. E. Andersen, "Optimal analysis and improved design of planar transformer in high power dc-dc converters" IEEE Trans. on Ind. Elec., 2010.

[16] Z. Ouyang, Z. Zhe, O. C. Thomsen, M. A. E. Andersen and T. Björklund, "Planar integrated magnetics design in wide input range dcdc converter for fuel cell application" in Proc. IEEE ECCE, 2010. 